\title{
Inefficient understanding of non-factive mental verbs with social aspect in adults: comparison to cognitive factive verb processing
}

This article was published in the following Dove Press journal:

Neuropsychiatric Disease and Treatment

\author{
Elena-loanna Nazlidou' \\ Despina Moraitou' \\ Demetrios Natsopoulos ${ }^{2}$ \\ Vasileios Papaliagkas' \\ Elvira Masoura' \\ Georgia Papantoniou ${ }^{3}$ \\ 'Lab of Psychology, Department \\ of Cognitive and Experimental \\ Psychology, School of Psychology, \\ Aristotle University of Thessaloniki, \\ Hellas, Greece; ${ }^{2}$ School of Psychology, \\ University of Cyprus, Nicosia, Cyprus; \\ ${ }^{3}$ Department of Early Childhood \\ Education, University of Ioannina, \\ Hellas, Greece
}

\begin{abstract}
Introduction: Mental verbs denote inner mental states and are an important link between language and Theory of Mind ability conceptualized as mental state understanding. Non-factive mental verbs denote an obligation or intention and constitute a discrete class of mental verbs which are characterized by their social aspect. This study aimed to examine adults' ability to understand non-factive mental verbs with the social aspect as compared to cognitive factive mental verbs which denote a true event.
\end{abstract}

Methods: A total of 94 participants, aged 18-95 years, were examined using two tasks measuring non-factive and factive verb processing, respectively, and a working memory test.

Results: The results indicated that non-factive verbs process is at a significantly lower level than those of cognitive factives.

Conclusion: The inspection of the way adapted to process the non-factive verbs denoting obligation or intention, as well as the confirmation of a unifactorial structure of the task developed to measure non-factives' processing, showed that adults have a common pattern of non-factive mental verb understanding, which is based on heuristic ways of thinking and is not affected by working memory capacity and age.

Keywords: affirmation/negation, cognitive factive mental verbs, heuristic ways of thinking, non-factive mental verbs, verbs denoting obligation or intention

\section{Introduction}

\section{Mental verbs: definition, functions, and types}

Social cognition ${ }^{1-6}$ is the sum of the abilities that allow individuals of the same species (co-specifics) to interact with each another. It is based on a series of cognitive processes applied for the decoding and encoding of the social world. A well-known psychological construct that is considered to be the main dimension of social cognition is the Theory of Mind (ToM) ability. ToM is defined as a mental state understanding, social understanding, or mentalizing. ${ }^{7,8}$ Recent studies in the field of social and cognitive neurosciences have identified a series of more specific dimensions of ToM. ${ }^{9-11}$ Among them is the ability to generate appropriate inferences from linguistic material. ${ }^{12-15}$

Mental verbs, as a specific group of mental state terms, constitute a link between language and ToM. ${ }^{16,17}$ The role of mental verbs ${ }^{18}$ is mainly to denote inner mental states, such as think, know, remember, believe, regret, intend, forget, promise, etc. They are associated with important syntactic, pragmatic and semantic aspects. Specifically, the senses and the connotations associated with these verbs are particularly numerous and varied. The verb know, for example, could denote a recognition in some cases, whereas a
Correspondence: Despina Moraitou Lab of Psychology, Department of Cognitive and Experimental Psychology, School of Psychology, Aristotle University of Thessaloniki, 54 I24 Thessaloniki, Hellas, Greece

Tel/fax +30 23I 0201372

Email demorait@psy.auth.gr (c) (1) (5) 2018 Nazlidou et al. This work is published and licensed by Dove Medical Press Limited. The full terms of this license are available at https://www.dovepress.com/terms.php (c) hereby accept the Terms. Non-commercial uses of the work are permitted without any further permission from Dove Medical Press Limited, provided the work is properly attributed. For permission for commercial use of this work, please see paragraphs 4.2 and 5 of our Terms (https://www.dovepress.com/terms.php). 
conjecture or a realization in some others. ${ }^{18}$ Moreover, mental verbs have multiple pragmatic functions, ${ }^{19}$ such as connecting words to real-world knowledge (eg, understanding what the use of mental verbs presupposes), maintaining text coherence (eg, bridging the unstated events in text), elaborating the text in order to achieve a richer mental model (eg, by figurative language) ${ }^{20}$ and indicating the speaker's attitude toward the statement in the subordinate clauses (eg, marking the degree of speaker's certainty). ${ }^{21,22}$ From the semantic point of view, mental verbs relate to the language of the mind, ${ }^{23}$ as they constitute the way through which insights into human cognition are provided. Also, through mental verbs, individuals connect to their own internal states, and their notions about internal states of others can be revealed. Despite the commonality that they have in terms of their role, mental verbs differ in a variety of dimensions, both continuous (eg, certainty-uncertainty) and discrete (eg, factivity, non-factivity). ${ }^{18}$

In line with this conceptualization, philosophers of language distinguish subclasses of mental verbs, depending on factivity or non-factivity they indicate. Factive mental verbs, ${ }^{24}$ such as know, remember, understand, and forget, denote a true event, which is described in the complement clause. On the contrary, non-factive mental verbs, such as promise, agree, and propose, denote an obligation or an intention. ${ }^{21,25,26}$ Factive verbs can differ from non-factive verbs, in that the former implies that the subject of the verb has unambiguous evidence, either perceptual or inferential, as regards the truth of the complement, whereas the latter implies that the subject does not have such evidence. ${ }^{27-29}$ According to Scoville and Gordon, ${ }^{28}$ factive verbs presuppose the veracity of the complements that follow. In this class of verbs, when they are constructed with a complement sentence, the truth of the complement sentence is implied, while the truth of the proposition expressed by the main sentence verb is presupposed. ${ }^{29-31}$ Non-factive verbs do not presuppose the veracity of the complements that follow, as a speaker cannot commit herself to the truth of the complement sentence following these verbs. ${ }^{30,31}$

In particular, from the philosophical point of view, knowledge is distinguished as the main member of the factive mental states, whereas other factive mental states such as "perceiving that ..." or "seeing that ..." simply represent more specific ways of "knowing that ...." 32 On the other hand, the linguistic perspective uses the term "factive" more restrictively as compared to philosophers, in terms of strictly reserving the term for predicates that presuppose the truth of their complements. Hence mental verbs that do not follow this presupposition, such as the verbs "think", "hope", "imagine", "assume", "believe", are considered nonfactive. ${ }^{32,33}$ Furthermore, non-factive verbs differ from factive verbs in their question-embedding capacity probably because the semantic contribution of the embedded question is only the true answer to that question. ${ }^{34}$ Based on linguistic studies, both the phenomena of "presupposition" and "embedding" are cross-culturally robust. ${ }^{32}$

Specific types of non-factive mental verbs such as the "commissives" (eg, "promise"), which denote an obligation or intention, could be further characterized by their social aspect. ${ }^{21,25,26}$ This means that besides non-factivity, such verbs may present increasing difficulty in their processing when the social context in which they refer is not known. On the other hand, the successful processing of such verbs seems crucial for the development and maintenance of ToM precisely because of their social aspect. In this light, this study aimed to examine whether adults' ability to process non-factive mental state verbs which denote an obligation or intention differs from their ability to process factive mental verbs.

\section{Mental verbs processing during lifespan development and aging: the role of age and working memory capacity}

With regard to the role of mental state terms in ToM development, recent research has shown that young children acquire ToM abilities at an earlier age (before the end of preschool years where they can contemplate correctly for most of the mental states), if their parents frequently use expressions referring to mental states when talking to their infants. ${ }^{19,35}$ Developmental research has indicated that the use of mental state terms begins approximately at the age of three and continues to develop throughout the school years. ${ }^{36-39}$ However, despite their use from an early age, it seems that young children (less than 4 years old) may induct mental terms for certain conversational function, but they do not possess the ability to understand mental states themselves. . $^{37,40,41}$

In relation to the acquisition of mental verbs, it is wellestablished that verbs, as content words, emerge later than nouns. The verb system is the most distinct of all speech categories because a prevalent feature of it is diversity linked with a constellation of properties, such as morphology, syntax, semantics, and pragmatics. ${ }^{42}$ Regarding these properties, mental verbs constitute a particular subgroup of verbs. ${ }^{22}$ In a recent study, ${ }^{22}$ the acquisition of mental verbs and its relationship with working memory in typically developing children (TDC), aged 8-12 years, and in children with specific language impairment (SLI) of the same age were 
investigated. To assess language ability, the researchers administered five tasks examining mental verbs' production and comprehension. Results indicated that children with SLI had more difficulties in the acquisition of mental verbs. The researchers suggest that this inefficiency occurs because children with SLI are less able to process and store phonological information in working memory and long-term lexicon.

Using a task where children had to judgemental verbs regarding factivity or non-factivity they indicated, the same researchers ${ }^{22}$ observed that the children with SLI witnessed difficulty in performing the twofold computation that is needed for this judgment. Specifically, the data provided evidence that they did not infer the truth of an event which was described in a complement clause, when the verb in the main clause was either explicitly (know) or implicitly positive (remember) or implicitly negative (forget). They, also, found it difficult to reason whether the action that was described in the complement clause, following the mental verb of the main clause, could be an intended or probable event, something that is attributed by the researchers to possible existence of pragmatic reasoning impairments. Despite the fact that group differences were significant in favor of the older TDC, the researchers conclude that it is noteworthy that older TDC performance in this task was low compared with other tasks (ie, mental verb sentence completion task with minimal context), something that could indicate that this task was extremely demanding. Working memory revealed as the most robust discriminate index of classification for all tasks.

Acquiring knowledge of mental verbs has to be conceived of as a long-term process with children's understanding being limited compared to adults' understanding, since adults have richer grammatical, semantic and syntactic knowledge, and also can have better representations of reality. ${ }^{43-45}$ In this light, adults appear to understand the relation between a mental reference itself and the conversational function, and also their semantic presuppositions. ${ }^{37}$ With regard to the developing organization of mental verbs, Schwanenflugel et al ${ }^{46}$ suggest that adults organize mental verbs in a continuous way, ranging from input functions (eg, notice, observe) to output functions (eg, decide, explain), through cognitive processing and memory functions (eg, question, learn). Moreover, the results of the same study indicated that adults organize verbs according to the degree of uncertainty involved in the information processing system about a mental verb. Verbs in the highly certain end, such as know, ranged through verbs of moderate uncertainty, such as think, to verbs of high uncertainty, such as guess. The verbs toward the uncertain end seemed to be also rated as relying more heavily on infer- ence and requiring information less readily available for their processing than other verbs.

With regard to the potential effects of age on lifespan development of mental verb processing and organization, the language in old age has been an active research area, in a broader level. At least six well-developed theories of cognitive aging and the respective empirical research suggest that age is negatively associated with specific aspects of language processing, mainly due to age-related cognitive declines and/or sensory reductions, such as resource deficits, general slowing, inhibition deficits, transmission deficits, declining working memory, and/or sensory/perceptual deficits. ${ }^{47}$

Among linguistic deficiencies related to aging, interpretation of syntactically complex sentences and sentence comprehension when the sentence is given in negative form seem prominent. ${ }^{48}$ A possible explanation of negation-related deficiencies of older adults is that impaired frontal white matter systems which support executive control abilities such as working memory are required for accurate processing of sentential negation. ${ }^{48}$ Moreover, potential impairment of the left perisylvian language areas and the left inferior parietal cortex could also explain the same deficiency ${ }^{48,49}$ Nevertheless, besides language aging, behavioral and neurophysiological research in adults explicitly indicates costly processing of sentences including negation compared to their affirmative counterparts. ${ }^{48,49}$

Among psychological constructs and functions, it is wellestablished that a cognitive function that plays a crucial role in language processing is working memory. ${ }^{50-54} \mathrm{Kemper}$ and Kemtes $^{54}$ argue that language and other cognitive functions share the same working memory capacity resources, usually measured with traditional span tasks. Waters and Caplan, ${ }^{55}$ however, argue for a specific working memory component that is specialized for online interpretive processing of sentences (ie, resolving syntactic structure and the meaning of the sentence), is not seriously affected by age, and is not related to traditional memory span measures. On the other hand, from the standpoint of this theory ${ }^{55}$ traditional measures of working memory span are related to conscious and controlled post-interpretive processes that are involved only in offline tasks (ie, plausibility judgments) and that are affected by memory processes. Interestingly, recent studies on this field resulted in evidence that argues against language-independent working memory effects in sentence processing. ${ }^{56,57}$

\section{Present study}

This study was designed to examine adults' ability to understand the indeterminate "nature" of non-factive mental verbs with the social aspect, as compared to their ability to 
process cognitive factives. Moreover, the study aimed to investigate the effects of age and working memory capacity on this ability.

Given the indeterminate "nature" of non-factive mental verbs with social aspect, the first hypothesis of the study was that performance of adults in non-factive verb understanding, as the ability to draw inferences from this type of verbs, should be lower from their ability to draw inferences from factive mental verbs (Hypothesis 1a).

At a qualitative level, due to the general human preference for decreasing uncertainty inherent in life and solving problems, ${ }^{11,58}$ it was expected that potential wrong inferences from non-factive mental verbs might be classified according to the consistency with which the action of the verb of the complement clause was wrongly attributed only to a particular person of the two persons mentioned in the main clause (Hypothesis 1b). In other words, the human need for eliminating uncertainty in combination with high demands in processing might lead adults to adopt heuristic ways of thinking to draw inferences from non-factive verbs with the social aspect.

Due to age-related deficiencies and the cognitively costly processing of sentential negation, it was assumed that performance of adults in non-factive verb understanding should be reduced when the verbs are given in negative form as compared to affirmation. The same was expected for factive verb understanding (Hypothesis 1c).

Due to high-level demands of cognitive processing of non-factive mental verbs, it was hypothesized that their understanding should be negatively affected by age (Hypothesis 2).

Based on the aforementioned theories of the relationship between working memory, language, and sentence comprehension, it was assumed that understanding of non-factive mental verbs with social aspect, as a post-interpretive process of drawing inference from such a verb, could be positively affected by working memory capacity measured as working memory span (Hypothesis 3).

To examine the hypotheses of the study, two tasks, developed in the Greek language to measure mental verb understanding as the ability to draw inferences from mental verbs, were used. The first one was designed to examine the ability to draw inferences from non-factive mental verbs which denote an obligation or intention, given either in affirmation or negation. The social aspect of these verbs becomes obvious in this task because each mental verb is put into the main clause, followed by a complement one. The subject of the complement clause, which is not explicitly given, cannot be determined since the social context in which the communication takes place is not known. Hence, it could be identified either with the subject of the main clause or with the person to whom the mental verb of the main clause is addressed. In other words, in the Greek language, in which the verb of the complement clause is given in the singular and the subject of this clause is omitted, there is ambiguity concerning the subject of the complement clause in terms of which of the two persons involved in the main clause is the subject of the complement clause [eg, "Petros proposed Nikos to travel later". In Greek, the subject of the complement clause "to travel (in singular) later" could be either Petros or Nikos]. Similar ambiguity, when the verb "propose" indicates intention, is also found in English [eg, "What do you propose to do now?". The subject of the infinitive clause (we, you, etc.) should be inferred from the context in which the sentence containing the infinitive occurs]. While there is not much research on the specific type of non-factive verbs, the existing literature on the cross-lingual use of factive and non-factive verbs suggests that there are cross-linguistic regularities which reflect a common underlying conceptual structure for verbs meaning "Know" (factives) and verbs meaning "think" (non-factives). . $^{32,34}$

Another task was designed to examine the ability to draw inferences from factive mental verbs which denote knowing or not knowing something, that is, to draw implications that the event described in the complement clause is true or not. They are given either in the affirmative form or negation (see details for the two tasks in the Methods section as well as in the Appendix in the Supplementary materials).

To examine Hypothesis 3, a task designed to test the functions of the central executive component of working memory was used. Taking into account that frontal systems supporting executive function are involved in linguistic deficiencies with age and sentence comprehension, we decided to use such a task because we were interested to measure the ability of the supervisory system of working memory to control the flow of information from and to its slave systems that can be involved in mental verb processing, namely the phonological loop, the visuo-spatial sketchpad, and the episodic buffer..$^{59}$

\section{Methods}

\section{Participants}

The sample comprised 94 adults from Greece, who participated voluntarily in the study. With regard to the age of the participants, they were divided into three broad age groups: young adults, middle-aged adults, and older adults (in fact, 
this age group consisted of two subgroups, the young-old adults and the old-old adults) (see Table 1). Participants were almost equally distributed in each one of the age groups in terms of their gender, $\chi^{2}(3,94)=0.31, P>0.05$. Regarding the educational level, due to the inclusion of eight very old persons (old-old adults) in the older adult group, irrespective of their educational level, as well as to the fact that low educational level was not represented in young and middleaged participants, the age groups differed significantly: young adults and middle-aged adults were of higher educational levels, as compared to older participants (young-old and oldold adults), $\chi^{2}(9,94)=34.51, P<0.001$ (see Table 1 ).

The sample of the 94 participants was the final one, after the exclusion of persons who met the exclusionary criteria used in the study. Exclusionary criteria for all participants were the presence of uncorrected hearing or visual loss, and a history of mental illness or substance abuse. Additional exclusion criteria for the older adult participants were a MiniMental State Examination (MMSE) score of less than 2760,61 and a Geriatric Depression Scale (GDS) - 15 scores of more than eight. ${ }^{62,63}$ A strict criterion for the exclusion of youngold adults on the basis of their MMSE score was adopted, considering that MMSE score of 23/24 was confirmed as an optimal cutoff level for the diagnosis of dementia in Greece $^{60,61}$ (see Table 1). However, an MMSE score of less than 23/24 was kept as an exclusion criterion for old-old adults (see Table 1). On the other hand, taking into account the financial crisis in Greece, a relatively flexible criterion for exclusion of the older adult participants according to their GDS-15 score was adopted, considering that GDS- 15 score " $6 / 7$ was confirmed as a valid cutoff level for the diagnosis of older adults" depression in Greece. ${ }^{62,63}$

\section{Measures}

\section{Social Mental Verb Understanding Task (SMVUT)}

The task was developed by Natsopoulos ${ }^{22,64}$ as a part of a broad battery aiming at examining different aspects of ToM. It was designed to examine a person's ability to draw inferences from non-factive mental verbs with the social aspect. It includes three non-factive mental verbs (promise, propose, agree). All the linguistic constructions with these verbs complied with the same syntactic pattern: the main clause verb was in past tense in indicative mood (third person singular), and the dependent clause verb in past tense in the finite subjunctive mood (third person singular) introduced by the particle "na". In all constructions, the agent (the grammatical subject) of the main clause was a proper name in the nominative case (the $\mathrm{X}$ ) and the addressee (the grammatical object)

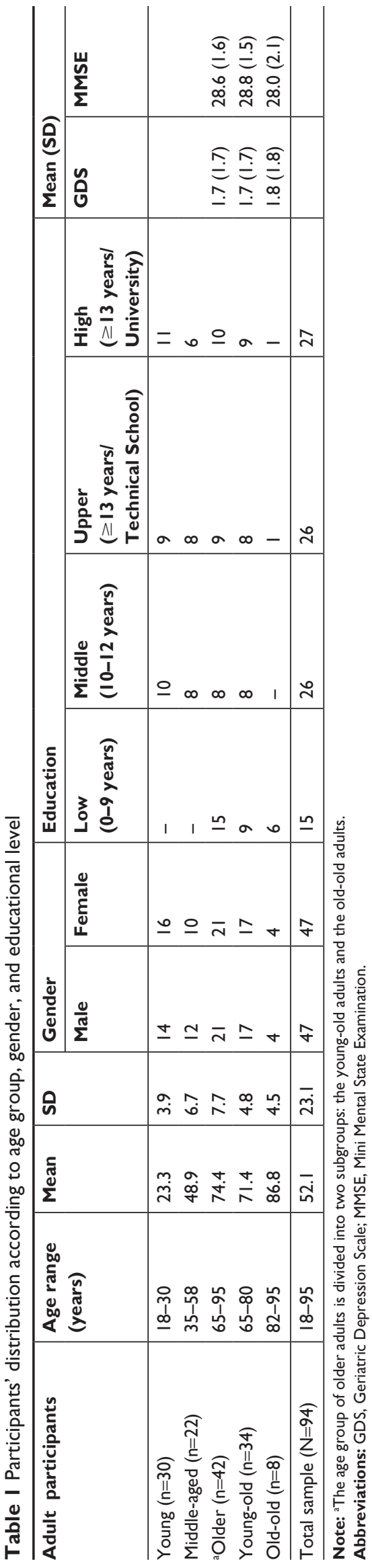


in the accusative case (the Y). In all the dependent clauses the agent (the grammatical subject) is omitted (dropped) in Greek in reported speech (see the example below and the sample of the linguistic constructions provided in the Appendix in the Supplementary materials). Thus, the reader in order to figure out who might be the potential agent of the "intended action" reported by the dependent clause verb, ie, the grammatical subject (the $\mathrm{X}$ - the speaker) or the grammatical object (the $\mathrm{Y}$ - the addressee) or both, she has to exploit syntactic cues and take into account social world knowledge (how "propositions", "promises", and "agreements" implicate mutually binding obligations in everyday interpersonal relations).

An example item is the following:

"Pavlos proposed Tasos to travel later.

Who might have traveled later?

1a. Tasos (the Y)

1b. Pavlos (the X)

1c. I cannot decide who might have traveled later."

\section{Cognitive Mental Verb Understanding Task (CMVUT)} It was also developed by Natsopoulos 22,64 as "control task" for the SMVUT. Specifically, the CMVUT was designed to examine a person's ability to draw inferences from factive mental verbs. It includes three cognitive mental verbs (know, remember, forget). The syntactic pattern of the linguistic constructions with the factive mental verbs was different from that with the non-factive verbs. The main clause verbs for "forget" and "remember" in affirmative and negative forms were in past tense in indicative mood (third person singular) followed by a dependent clause with a transitive verb in subjunctive mood (third person singular) introduced with the particle "na" also in past tense. The agent of the main clause verb (the grammatical subject) was also the agent of the dependent clause transitive verb which reported an action or a result brought out positive or negative, respectively. In the case of the verb "know", the dependent clause was introduced by the particle "that" and served as the grammatical object (nominal) of the main clause (cf. sampling in the Appendix in the Supplementary materials).

An example item of the task is the following:

"Chrisanthi did not remember to pay the mortgage installment.

Is it true that:

1. the mortgage installment was not paid

2. the mortgage installment might have not been paid

3. the mortgage installment was paid."

The 24 (12 and 12) stimulilinguistic constructions of the SMVUT and CMVUT (two instances in affirmative and two in negative pattern for each verb) were presented in a written form one at a time to the examinee in a pseudo-randomized order with a restriction: no constructions of the same pattern were allowed to follow consecutively. The examinee, after reading carefully each construction with the non-factive verbs, had to choose who might perform the action stated by the dependent clause verb by circling one of the three choices: (a), (b), and (c). The correct answer - which was only the one that assigned both as agents of the action stated by the dependent clause, ie, "(c) I cannot decide who might have invited a lot of friends" - for each linguistic construction is credited with " 1 " point. Thus, the score for each non-factive verb given in the affirmative or the negative form only could range from " 0 " to " 2 " points.

For the factive cognition mental verbs, the examinee had to choose also by circling the answer she/he judged correct. The correct answer, ie, "(a) the mortgage installment was not paid", is credited with " 1 " and all other answers are scored with " 0 ". Thus, the score for each verb given in the affirmative or the negative form only could range from " 0 " to " 2 ".

\section{Working memory task: Short-Term Retention and Processing Task: Central Executive Functions (STRPT: CEF)}

The task involves a listening recall paradigm. An example item is the following:

"Goldfish have fur.

Correct response: false/fur."

The task was designed based on the working memory battery of Pickering and Gathercole, ${ }^{65}$ to test the functions of the central executive component of working memory. Previous research demonstrated very good psychometric properties ${ }^{66}$ of the task. Participants are asked to listen to a sentence and then judge whether its content is true or false. After doing so for all sentences in a set, they have to repeat the last word of all sentences in the serial order they were presented in the set. Each span includes six trials, and if they answer four correctly, they advance to the next span level. If they answer three or fewer out of six trials incorrectly, the test is discontinued. The variable of interest is the largest span achieved. This task is a dualprocessing task and is administered to assess storage capacity and dual processing ${ }^{67}$ of verbal information. For the present study, a total score for working memory capacity was estimated depending on the span level that the participant reached. Thus, the score for the task could range from " 1 " to " 9 ".

\section{Procedure}

Participants were examined on an individual basis, in two sessions, in a place of their choice, while ensuring that 
every session was conducted in a quiet environment with no interruptions during the testing. Each session lasted approximately 120 minutes. All participants were examined by the same researcher (Nazlidou). The test was more timeconsuming for old-old adult participants because of their need to take frequent breaks.

\section{Ethical standards}

The authors assert that all procedures contributing to this work comply with the ethical standards of the relevant national and institutional committees on human experimentation and with the Helsinki Declaration of 1975, as revised in 2008. After reviewing the research protocol the Ethics Committee of the School of Psychology of the Aristotle University of Thessaloniki confirmed that all ethical guidelines for research on human subjects were followed.

At the beginning of each experimental session, participants were informed that the study was voluntary and they could withdraw from the study any time they wanted without providing any further explanation, and their responses would be kept confidential. All participants gave written informed consent. The participant's consent forms were collected before they were given the tasks and were kept separately to avoid subject identification.

\section{Statistical analysis}

At the first level, data analysis was conducted in SPSS version 21. ${ }^{68}$ The analyses carried out were repeated-measures ANOVA. The general aim of these analyses was to compare: 1) task performance for non-factive mental verbs given in affirmation vs negation; 2) task performance for factive mental verbs given in affirmation vs negation; 3) task performance for factive vs non-factive mental verbs. Levene's test was used to assess the equality of variances, Box's test for equivalence of covariance matrices, and Mauchly's test of sphericity of within-subject factor. Greenhouse-Geisser was adopted for correcting against violations of sphericity. Finally, partial eta-squared was used for the estimation of the effect size.

Data analysis was continued with structural equation modeling (SEM) techniques. ${ }^{69}$ Specifically, in order to examine whether there are any underlying dimensions of non-factive mental verb understanding, based on which performance on the SMVUT was formulated, the data were subjected to confirmatory factor analyses (CFAs). These analyses, as well as all the SEM techniques that will be presented in the Results section, were conducted in EQS Version 6.1.69 Because of data kurtosis, SEM techniques were performed on covariance matrices using Robust
Maximum Likelihood estimation procedure. ${ }^{69-72}$ Model fit was evaluated based on the Satorra-Bentler scaled chisquared statistic as well as on the root mean squared error of approximation (RMSEA); a rule of thumb is that RMSEA values $<0.05$ indicate close approximate model fit, while RMSEA values $>0.06$ and $<0.08$ indicate a reasonable error of approximation and adequate model fit. Additional support for the fit of the solution would be evidenced by a $90 \%$ CI of the RMSEA whose upper limit is below the cut-off values of $0.08-0.10 .^{70}$ However, at this point it should be mentioned that the width of the CI for RMSEA is affected by sample size (eg, when $\mathrm{N}<100$ ) and the number of freely estimated parameters. Thus, in such cases, the values and the width of the $90 \%$ CI for RMSEA should be treated cautiously and with less concern, if all other indices are strongly in a range of supporting "good" model fit. ${ }^{70,71}$ The Comparative Fit Index (CFI) was also used; CFI values greater than 0.95 indicate a good fit of the researcher's model. ${ }^{70,72}$ Moreover, to improve model fit, we examined the modification indices, namely the Wald and the Lagrange tests, which represent frequently used statistics to identify focal areas of a misfit in a CFA solution. ${ }^{70,72}$

Subsequently, to test the effects of age and working memory on the SMVUT, the Multiple Indicators Multiple Causes (MIMIC) modeling was used. In MIMIC models, both the latent factor and indicators are regressed onto exogenous variables - covariates added to the CFA model established previously. Thus, besides indicating population heterogeneity, MIMIC models can detect differential item functioning (DIF), that is, a statistical characteristic of an item that shows the extent to which the item might be measuring different abilities for members of separate subgroups. ${ }^{70,73}$ Specifically, to assess direct associations between the covariates (age, working memory) and the indicators of the latent factor, for each covariate, all paths towards the indicators of the latent factor were constrained to zero. The modification indices were then examined since they indicate how much the fit of the model would be improved if the paths were freely estimated. ${ }^{70,73}$

\section{Results}

\section{Non-factive vs factive mental verb task performance}

To find out how many adults possess a well-formulated level of non-factive mental verb understanding as the ability to draw inferences from non-factive mental verbs with the social aspect, the sum of scores concerning the three non-factive verbs given in affirmative form as well as the respective sum for the same verbs given in negation were calculated. Then 
Table 2 Participants' distribution according to scores regarding the ability to draw inferences from non-factive mental verbs with the social aspect

\begin{tabular}{l|l|l|l|l}
\hline \multirow{2}{*}{ SMVUT score } & \multicolumn{2}{|l|}{ Non-factive verbs in affirmative form } & \multicolumn{2}{l}{ Non-factive verbs in negative form } \\
\cline { 2 - 5 } & Frequency & Percent & Frequency & Percent \\
\hline 0 & 47 & 50 & 36 & 38.3 \\
1 & 21 & 22.3 & 13 & 13.8 \\
2 & 11 & 11.7 & 11 & 11.7 \\
3 & 8 & 8.5 & 13 & 13.8 \\
4 & 5 & 5.3 & 9 & 9.6 \\
5 & 2 & 2.1 & 8 & 8.5 \\
6 & - & - & 4 & 4.3 \\
\hline
\end{tabular}

Abbreviation: SMVUT, Social Mental Verb Understanding Task.

the percentage of participants credited with " 6 - the best possible score" was found (see Table 2).

As shown in Table 2, nobody $(\mathrm{n}=0)$ achieved the best possible performance as regards the ability to draw inferences from non-factive verbs given in affirmative form, while only $4.3 \%$ of the participants $(n=4)$ were credited with the best score for their ability to draw inferences from these verbs given in negative form. In fact, only $7.4 \%$ of the participants $(n=7)$ exceeded the average scores and were credited with " 4 " or " 5 " in the first case, while a relatively higher percentage of $22.4 \%(n=21)$ exceeded the average performance in the latter case (see Table 2). These results clearly showed that there are indeed very few adult participants who possess a wellformulated level of non-factive mental verb understanding.

Beyond this, it became clear that adults' ability to draw inferences from non-factive verbs given in affirmative form is reduced than the same ability when non-factive verbs are given in negation. The application of repeated-measures ANOVA to the data showed that there was indeed significant difference, $F(1,93)=31.21, P<0.001, \eta_{\mathrm{p}}{ }^{2}=0.25$ : performance in affirmation: $M=1.03, \mathrm{SD}=1.33$; performance in negation: $M=1.85, \mathrm{SD}=1.91$.

To compare adults' ability to draw inferences from nonfactive mental verbs with their ability to draw inferences from factives, the same procedure as described above was followed for these verbs as well (see Table 3). The sum of scores concerning the three factive verbs is given in the affirmative form and the respective sum for the same verbs given in negative form was calculated. Then the percentage of participants credited with " 6 - the best possible score" was found.

The results showed that $72.3 \%$ of the participants $(n=68)$ were credited with the best possible score as regards their ability to draw inferences from factive verbs given in affirmative form, and $39.4 \%$ of them $(n=37)$ were credited with the best score for their ability to draw inferences from factive verbs given in negation. However, another 26.6\% of the participants $(n=25)$ were found able to overcome the average performance and be credited with " 4 " or " 5 " in the first case, while a high percentage of $57.4 \%(n=54)$ exceeded the average performance in the latter case (see Table 3).

Furthermore, adults' ability to draw inferences from factive verbs given in affirmation was found higher than the same ability when factive verbs are given in negation. The application of repeated-measures ANOVA to the respective data showed that there was significant difference, $F(1,93)=29.15, P<0.001, \eta_{\mathrm{p}}{ }^{2}=0.24$ : performance in affirmation: $M=5.65, \mathrm{SD}=0.63$; performance in negation: $M=5.07$, $\mathrm{SD}=0.94$. At this point, it must be noted that this finding is the inverse to what was found for non-factive mental verb understanding.

Table 3 Participants' distribution according to scores regarding the ability to draw inferences from cognitive factive mental verbs

\begin{tabular}{l|l|l|l|l}
\hline CMVUT score & \multicolumn{2}{|l|}{ Factive verbs in affirmative form } & \multicolumn{2}{l}{ Factive verbs in negative form } \\
\cline { 2 - 5 } & Frequency & Percent & Frequency & Percent \\
\hline 0 & - & - & - & - \\
1 & - & - & 1 & 1.1 \\
2 & - & - & - & - \\
3 & 1 & 1.1 & 2 & 2.1 \\
4 & 5 & 5.3 & 22 & 23.4 \\
5 & 20 & 21.3 & 32 & 34.0 \\
6 & 68 & 72.3 & 37 & 39.4 \\
\hline
\end{tabular}

Abbreviation: CMVUT, Cognitive Mental Verb Understanding Task. 
Moreover, based on the findings, it seems obvious that contrary to what happens in the case of non-factive mental verbs, adults possess a high level of factive mental verb understanding. The application of repeated-measures ANOVA to the total scores for non-factive and factive verbs showed that there was significant difference, $F(1,93)=457.51, P<0.001$, $\eta_{\mathrm{p}}{ }^{2}=0.83$ : non-factive verb performance: $M=2.88, \mathrm{SD}=0.2 .97$; factive verb performance: $M=10.72, \mathrm{SD}=1.23$. Mean factive verb performance was found almost excellent, given that the best possible total score was " 12 ".

To examine whether wrong inferences from nonfactive mental verbs were classified according to some kind of consistency with which the action of the verb of the complement clause was wrongly attributed in a certain of the two persons mentioned in the main clause of each sentence of the SMVUT, the frequency with which every wrong answer was selected for each of the three non-factive verbs in affirmative and in negative form was calculated. For the verb "propose" given in the affirmative form, the action of the verb of the complement clause was attributed to the subject of the non-factive verb in the main clause 43 times and to the other person in the main clause 114 times. For the verb "agree" given in the affirmative form, the action of the verb of the complement clause was attributed to the subject of the non-factive verb in the main clause 108 times and to the other person 24 times. For the verb "promise" given in the affirmative form, it was attributed to the subject of the non-factive verb 146 times and to the other person 19 times.

For the verb "propose" given in negation, the action of the verb in the complement clause was attributed to the subject of the non-factive verb in the main clause 27 times and to the other person in the main clause 96 times. For the verb "agree" given in the negative form, it was attributed to the subject of the non-factive verb 61 times and to the other person 53 times. For the verb "promise" given in the negative form, it was attributed to the subject of the non-factive verb in the main clause 74 and to the other person 54 times. In general, these findings indicated that the consistency with which the action of the verb of the complement clause was wrongly attributed in a certain of the two persons mentioned in the main clause of each sentence of the SMVUT appeared to be at a higher level when non-factive verbs were given in the affirmative form than when the same verbs were given in negation.

\section{The factorial structure of the SMVUT}

Taking into account the findings above showing a very low level of nonfactive mental verb understanding in adults and revealing differences in understanding due to the form in which the verb is given (affirmative, negative), it was deemed necessary to proceed to examine the underlying factorial structure of the SMVUT.

Table 4 presents the mean performance of the total sample for each observed variable - subtask of the SMVUT. In general, inspection of the mean scores reveals that the means for all subtasks of the SMVUT are very low, given that the best possible score is "2". There is also a sample kurtosis.

To validate the factorial structure for the SMVUT, two alternative CFA models were examined. We firstly tested a single-factor model of the SMVUT in which the six observed variables were set to load on one factor labeled "Non-factive Verb Understanding" (measurement model "A"). The fit indices of the model were as follows: Satorra-Bentler scaled $\chi^{2}(9$, $\mathrm{N}=94)=19.38, P<0.05 ; \mathrm{CFI}=0.92 ; \mathrm{RMSEA}=0.11(90 \% \mathrm{CI}$ : $0.04-0.17)$. So, the fit indices indicated that this factor as it was defined represented a model that did not fit the data adequately. Therefore, based on the examination of the modification indices, a unifactorial model in which two observed variables were allowed to correlate with each other was tested (structural model "A"). This model yielded an acceptable fit: the chi-squared goodness of fit test was not statistically significant, resulting in the acceptance of the null hypothesis of good fit, Satorra-Bentler scaled $\chi^{2}(8, N=94)=11.44$, $P=0.30$. The CFI was 0.98 , indicating strongly reasonable fit, and the RMSEA was 0.07 (90\% CI: $0.00-0.15)$, indicating acceptable fit for the model (see Figure 1). As regards internal consistency of the latent variable, Cronbach's alpha was 0.82 . The observed variables "propose in affirmative form" and "agree in affirmative form" were the two variables allowed to correlate with each other. Inspection of the standardized solution revealed that all the indicators had high enough loadings $(>0.50)$ on the latent factor.

Given that there is preliminary evidence ${ }^{64}$ about a twofactorial structure of the SMVUT in adults, indicating that adults process non-factive mental verbs in a way that varies depending on the form (affirmative, negative) in which the verb is given, a CFA model with two factors was also

Table 4 Mean performance of the sample $(\mathrm{N}=94)$ on the subtasks of the SMVUT

\begin{tabular}{l|l|l|l|l}
\hline SMVUT subtasks & Mean & Skewness & Kurtosis & SD \\
\hline Propose/affirmative & 0.32 & 1.60 & 1.60 & 0.57 \\
Propose/negative & 0.60 & 0.85 & -0.88 & 0.79 \\
Agree/affirmative & 0.51 & 0.98 & -0.29 & 0.68 \\
Agree/negative & 0.72 & 0.55 & -1.29 & 0.82 \\
Promise/affirmative & 0.20 & 2.33 & 4.71 & 0.48 \\
Promise/negative & 0.53 & 0.90 & -0.39 & 0.68 \\
\hline
\end{tabular}

Abbreviation: SMVUT, Social Mental Verb Understanding Task. 


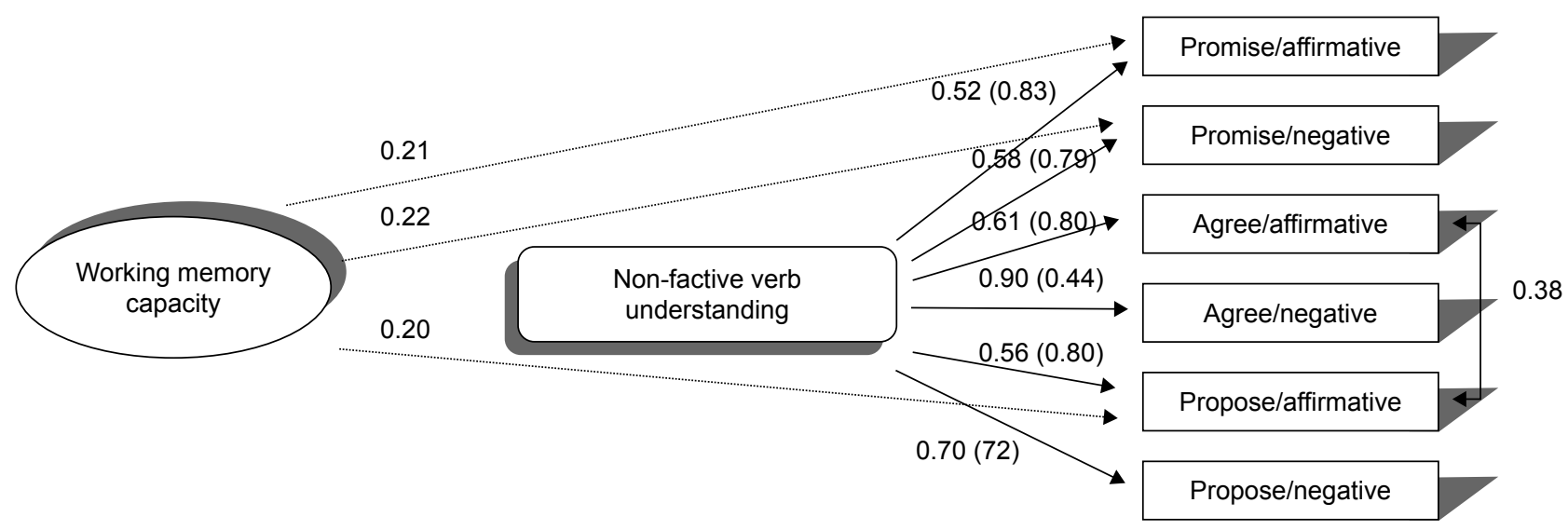

Figure I MIMIC model examining the impact of working memory capacity on the underlying structure of the SMVUT standardized solution.

Notes: All paths drawn indicate significant associations $(P<0.05)$. Errors are shown in parentheses.

Abbreviations: MIMIC, Multiple Indicators Multiple Causes; SMVUT, Social Mental Verb Understanding Task.

tested in this study. Hence, a two-factor model was tested in which the three observed variables referring to non-factive verb understanding, when the verbs are given in affirmative form, were set to load on one factor labeled "Understanding of Non-factive Verbs in Affirmative Form". The remaining three variables referring, respectively, to understanding of each one of the same verbs in negation were set to load on a second factor labeled "Understanding of Non-factive Verbs in Negative Form" (measurement model "B"). Model "B" was not confirmed, Satorra-Bentler scaled $\chi^{2}(9$, $\mathrm{N}=94)=54.58, P<0.001 ; \mathrm{CFI}=0.67 ; \mathrm{RMSEA}=0.23(90 \%$ CI: $0.17-0.29)$. When the two latent factors were allowed to correlate with each other (structural model "B"), the fit indices of the model were somewhat improved but they still indicated non-acceptable fit, Satorra-Bentler scaled $\chi^{2}(8$, $\mathrm{N}=94)=17.06, P<0.05 ; \mathrm{CFI}=0.93 ; \mathrm{RMSEA}=0.11(90 \%$ CI: $0.03-0.18)$. Moreover, the two factors highly correlated $(r=0.87)$; that was also observed in the preliminary study ${ }^{64}$ and arose a serious issue as regards the conceptual differentiation between them (see also Supplementary material S1). In addition, according to the modification indices, one of the observed variables set to load on one factor should be set to load on the other factor as well. Thus, the twofactorial model of the SMVUT was found to display areas of misfit.

\section{The effects of age on non-factive verb understanding}

Once acceptable fit of the unifactorial CFA model was obtained, we tested a MIMIC model in which age group was entered into the structural model "A" and allowed to covary with the latent factor. The Wald test was used to examine the need for the regression and suggested dropping the regression onto age group. Moreover, no indicator was directly associated with the covariate (see also Supplementary material S2).

\section{The effects of working memory capacity on non-factive mental verb understanding}

As mentioned in the Methods section, a total score for working memory capacity as short-term retention and dual processing (STRPT: CEF) was estimated depending on the span level that the participant reached: the mean score in the STRPT: CEF for the total sample was $2.43(\mathrm{SD}=0.91$, range $=1-5)$. Forty participants $(42.6 \%)$ reached the second span level and $31(33 \%)$ reached the third span level.

To examine the effects of working memory capacity on the SMVUT, we tested a MIMIC model in which memory span was entered into the structural model " $\mathrm{A}$ " and allowed to correlate with the latent factor. The Wald test, which was used to examine the need for the regression, suggested dropping the regression onto working memory measure. To assess direct associations between the covariate and the indicators of the factor, all paths from memory span variable towards the indicators of the latent factor were constrained to zero. The modification indices were then examined. Three indicators were directly associated with the covariate. As shown in Figure 1, the understanding of the verbs promise and propose in affirmation, and the understanding of the verb promise in negation means $(M)$ were different in different levels of 
working memory capacity, with lower memory span to relate to a lower level of the ability to understand the indeterminate "nature" of the specific non-factive verbs. The MIMIC model finally confirmed yielded a good fit, Satorra-Bentler scaled $\chi^{2}(11, \mathrm{~N}=94)=13.70, P=0.25 ; \mathrm{CFI}=0.98 ; \mathrm{RMSEA}=0.05(90 \%$ CI: 0.00-0.12) (see Figure 1).

\section{Discussion}

\section{The level of non-factive mental verb understanding in adults as compared to factive verb processing}

Although language has a serious influence on social interaction in general, especially on ToM performance, ${ }^{39,74}$ empirical studies examining non-factive mental verb processing in adulthood are extremely limited. The present study tried to fill the gap that exists as concerns adults' ability to understand the social factor and the "indeterminate" nature of non-factive verbs denoting obligation or intention, 1) by comparing the processing of non-factive and factive verbs and 2) by revealing the way according to which adults process non-factive verbs with social aspect from young adulthood to aging. The results indicated that adults are, in general, inefficient to process non-factive mental verbs with social aspect during the lifespan. Specifically, it seems that they are not able at all to "mentalize" in this case, that is, to understand that without the social context in which a specific sentence occurs, they cannot actually find the person who might act as the subject of the complement clause that follows the main clause including the non-factive verb. This inefficiency becomes more obvious when non-factive verb processing is compared with factive verb performance, in which almost all adults appear to be at a very high level. In other words, almost all of them are highly able to draw inferences about the truth of the complement clause that follows the main clause which includes the cognitive factive verb (Hypothesis 1a). The confirmation of Hypothesis 1a could lead to interesting implications concerning ToM abilities in adulthood: a person could make wrong attributions of mental states because she is not able to appropriately bind or integrate specific linguistic phenomena with her ToM abilities. ${ }^{14,16,17,32,39,40}$

This does not mean that adults do not understand the semantics or the meaning of non-factive mental verbs. ${ }^{32}$ However, it seems that they are not based on content-free syntaxsensitive inference rules, when they have to make inferences related to these verbs. They are based on heuristic ways of thinking such as pragmatic reasoning schemas, that is, context-sensitive rules having pragmatic import from recurring personal experience of a situation, or/and social contract schemas, namely capacities for recognizing and manipulating social contracts, to adapt to the environment. ${ }^{75}$

Moreover, discourse comprehension, in general, could occur through top-down processing and also by using the "real-world" knowledge. ${ }^{47}$ Furthermore, in order to comprehend a text, people tend to use situation models, which are multi-dimensional representations of the topic of the text that include information such as space, time, and causal relationships. ${ }^{76}$ In fact, a situation model goes beyond the literal content of the text by integrating the text with pre-existing knowledge. ${ }^{77}$ In this light, adult participants in the study appear to know from experience that, most times, the person who arranges an agreement or promises something is the performer of the action. In contrast, it is common to propose something for someone else, when it concerns themselves. For example, in a sentence it was given: "Pavlos proposed to Nikos to travel later". The answer most often given was that "Nikos might travel later", since the proposal was made on him (Hypothesis 1b).

The confirmation of a unifactorial structure for the SMVUT also verifies Hypothesis $1 \mathrm{~b}$, in terms of clearly indicating that adults are based on a common underlying pattern of thinking to process non-factive mental verbs with the social aspect. The unidimensional way of processing their use appears to be the application of relatively automatic heuristic methods based on their pre-existing knowledge for a specific verb, to make an inference about this verb at a given time.

Nevertheless, the positive correlation between the factor indicators - verbs "propose" and "agree", given in affirmative form - showed that besides general heuristics, adults may use specific heuristic ways in order to make judgments about specific verbs: in this case, for example, the participants might formulate their judgments about "propose" and "agree" on the basis of their conceptualization as potentially complementary verbs: thus, when a person "proposes" to someone something in the main clause, the action of the verb of the complement clause seems to be usually attributed to the person in the main clause who accepts the proposal. In contrast, when a person "agrees" with someone about something in the main clause, the action of the verb of the complement clause is usually attributed to the subject of the non-factive verb. A context that gives the opportunity to make inferences about these verbs through an implicit comparison between them may "facilitate" the heuristic inference finally given.

Important findings that concern both performances in non-factive and factive verb processing are that the overall score in non-factive verb processing was higher when 
the verbs were given in a negative clause, rather than in affirmation, while the inverse was observed for the factives. Hence Hypothesis 1c was partially confirmed.

The finding about the higher performance when the nonfactive verb was given in negation seems inconsistent, with the literature supporting that the negative form increases comprehension difficulty. ${ }^{48,49,77-80}$ Negative sentences seem to have more complex syntactic structure than affirmative ones, ${ }^{77-80}$ and neuroimaging studies have also revealed a greater brain activation (specifically, in inferior parietal cortex bilateral and in left premotor cortex) during the processing of negative sentences, rather than affirmative ones. ${ }^{80}$ However, based on the use of heuristics and pre-existing knowledge, one can state that when a "not" accompanies a non-factive verb, this could help and direct non-factive verb understanding via narrowing the possible answers and, somehow, marginalizing the meaning of the verb.

In any case, what is obvious from the findings of the present study is that the negative form of a cognitive factive verb increases somewhat the difficulty of verb processing. However, based on their scores, it seems that almost all the participants were able to process factive verbs in negation at a high level. Knowing the way in which adults organize their mental lexicon, this finding is not surprising: these are verbs of low uncertainty which impose low demands on information processing system. ${ }^{46}$ Inversely, based on the non-confirmation of a two-factorial model of the underlying structure of the SMVUT, it could be claimed that the indeterminate "nature" of the non-factive verbs denoting obligation or intention imposes serious difficulties in verb processing, which make less important the issue of verb form.

\section{The role of age and working memory capacity in non-factive mental verb understanding}

With regard to the effects of age on the understanding of non-factive mental verbs, the respective hypothesis was not confirmed (Hypothesis 2). The findings showed that age does not affect the ability to process these verbs, as older adults do not exhibit a lower level of understanding, compared to younger ones. Taking into account the low performance of all participants in the SMVUT, it could be suggested that nonfactive verb processing is at a very low level among adults and seems not to develop or decrease through their entire lifespan. A possible explanation is that they do not use cognitive resources, which decline with age, for this processing, as they seem to prefer to be based on their personal experiences with specific situations, or on social contracts. ${ }^{47,75}$
In the same vein, the results indicated that Hypothesis 3 was not confirmed in general, since working memory capacity measured as dual processing applied to verbal information was found to affect positively only specific verbs and forms of verbs: the verb promise in affirmative and negative forms, as well as the verb, propose, in affirmative form only. These findings, in association with the very low mean performance in the same verbs (see Table 4), indicated clearly that the "central executive" is recruited only when there is major difficulty to understand the indeterminate "nature" of nonfactive verbs using heuristic ways of thinking. In other words, when pre-existing knowledge and real-world experiences are considered non-adequate to process non-factive mental verbs, higher-order functions of the "central executive" are recruited to control attention while binding together information from slave storage systems of working memory, ${ }^{55,59,81,82}$ in order to make an inference. Future research should elucidate which non-factive verbs impose additional demands in processing, in what form, and why. However, at the methodological level, this is something that introduces a limitation related to the psychometric properties of the SMVUT, as the specific verbs should be replaced in a revised version of the task, due to DIF issues. ${ }^{70,72,73}$

With regard to a broader working memory capacity effect, the absence of such an effect could be attributed to the task which was selected to be used in this study. Mental verb understanding in children has found to correlate with phonological working memory and sentence comprehension, in general, is claimed to be affected by the visuospatial sketchpad and the episodic buffer..$^{22,81,82}$ Specifically, in the case of non-factive mental verb processing, taking into account that real-world experience and pre-existing knowledge appear to be important factors for make an inference, future research should examine the role of the episodic buffer, since this component can act as a "backup store" to supplement the other components of working memory, as well as to provide a link to long-term memory. ${ }^{83}$

\section{Limitations and future research}

This study has limitations. The restricted nature of the sample should be noted with regard to the number of participants in each age group. An additional limitation is the cross-sectional design of the study. It is unknown if the same pattern of results would be obtained in case the same participants were repeatedly measured at a different age. With regard to the instrument used to measure non-factive mental verb understanding, more verbs should be included in the SMVUT and methodological issues should be resolved. In a next step, 
interventions related to enhancing non-factive mental verb processing in children and adults should be designed, and non-factive verb understanding should be examined in relation to different dimensions of social cognition and multiple cognitive functions.

Nevertheless, this study was able to indicate that adults, from youth until the very old age, process non-factive mental verbs with social aspect in a common way, using heuristic methods based on pre-existing knowledge, realworld knowledge, and situational models. Hence, their ability to understand non-factive verbs remains low enough, especially when compared with their high-level ability to understand the factivity of cognitive mental verbs. A serious implication of this inefficiency may be that they could make wrong attributions of mental states, when they do not have enough information for the social context and are not able to appropriately bind the linguistic information with ToM abilities.

\section{Acknowledgments}

This work was supported by the Research Committee of the Aristotle University of Thessaloniki, Greece (Special Account for Research Implementation/87871/Moraitou). The funding source had no other involvement besides financial support in the conduct of the research and the preparation of the article.

\section{Disclosure}

The authors report no conflicts of interest in this work.

\section{References}

1. Adolphs R. Social cognition and the human brain. Trends Cogn Sci. 1999;3(12):469-479.

2. Beer JS, Ochsner KN. Social cognition: a multi level analysis. Brain Res. 2006;1079(1):98-105.

3. Adolphs R, Tranel D, Damasio H. Emotion recognition from faces and prosody following temporal lobectomy. Neuropsychology. 2001;15(3):396-404.

4. Barone DF, Maddux JE, Snyder CR. Social Cognitive Psychology: History and Current Domains. New York: Plenum Press; 1997.

5. Perner J, Wimmer H. "John thinks that Mary thinks that..." attribution of second-order beliefs by 5- to 10-year-old children. J Exp Child Psychol. 1985;39(3):437-471.

6. Wellman HM, Woolley JD. From simple desires to ordinary beliefs: the early development of everyday psychology. Cognition. 1990;35(3): 245-275.

7. Moran JM. Lifespan development: the effects of typical aging on theory of mind. Behav Brain Res. 2013;237:32-40.

8. Pezzuti L, Longobardi E, Rossetti S, et al. The relation between the Theory of Mind and socio-emotional functioning in a sample of older adults. J Neurol Psychol. 2015;3(2):1-7.

9. Kemp J, Després O, Sellal F, Dufour A. Theory of Mind in normal ageing and neurodegenerative pathologies. Ageing Res Rev. 2012;11(2): 199-219.
10. Moreau N, Rauzy S, Viallet F, Champagne-Lavau M. Theory of mind in Alzheimer disease: Evidence of authentic impairment during social interaction. Neuropsychology. 2016;30(3):312-321.

11. Moraitou D, Papantoniou G, Gkinopoulos T, Nigritinou M. Older adults' decoding of emotions: age-related differences in interpreting dynamic emotional displays and the well-preserved ability to recognize happiness. Psychogeriatrics. 2013;13(3):139-147.

12. Filik R, Hunter CM, Leuthold $\mathrm{H}$. When language gets emotional: irony and the embodiment of affect in discourse. Acta Psychol. 2015; 156:114-125.

13. Monetta L, Grindrod CM, Pell MD. Irony comprehension and theory of mind deficits in patients with Parkinson's disease. Cortex. 2009;45(8):972-981.

14. Nazlidou EI, Moraitou D. Theory of mind in aging: a critical presentation of contradictory findings and divergent views. Hellenic J Psychol. 2016;13:116-146.

15. Phillips LH, Allen R, Bull R, Hering A, Kliegel M, Channon S. Older adults have difficulty in decoding sarcasm. Dev Psychol. 2015; 51(12):1840-1852.

16. de Villiers JG, Pyers JE. Complements to cognition: a longitudinal study of the relationship between complex syntax and false-beliefunderstanding. Cogn Dev. 2002;17(1):1037-1060.

17. Hughes C, Leekam S. What are the links between Theory of Mind and social relations? Review, reflections and new directions for studies of typical and atypical development. Soc Dev. 2004;13(4):590-619.

18. Naigles LR. Manipulating the input: studies in mental verb acquisition. In: Landau B, Sabini J, Jonides J, Newport E, editors. Perception, Cognition, and Language. Cambridge, MA: MIT Press; 2000:245-274.

19. Harris PL, de Rosnay M, Pons F. Language and Children's Understanding of Mental States. Curr Dir Psychol Sci. 2005;14(2):69-73.

20. Spanoudis G, Natsopoulos D, Panayiotou G. Mental verbs and pragmatic language difficulties. Int J Lang Commun Disord. 2007;42(4): $487-504$.

21. Montgomery DE. Mental verbs and semantic development. $J$ Cogn Dev. 2002;3(4):357-384.

22. Spanoudis GC, Natsopoulos D. Memory functioning and mental verbs acquisition in children with specific language impairment. Res Dev Disabil. 2011;32(6):2916-2926.

23. Astington JW. Language and metalanguage in children's understanding of mind. In: Astington JW, editor. Minds in the Making: Essays in Honor of David R. Olson. Oxford: Blackwell; 2000:267-284.

24. Steinberg DD, Jakobovits LA. Semantics: An Interdisciplinary Reader in Philosophy, Linguistics and Psychology. Vol. 171. Cambridge, MA: Cambridge University Press; 1971.

25. Austin JL. How to do Things with Words. Cambridge, MA: Harvard University Press; 1962/1975.

26. Searle JR. Speech Acts: An Essay in the Philosophy of Language. Cambridge, NY: Cambridge University Press; 1969/1988.

27. Babu N. Development of Theory of Mind and Mental State Language in Children. New Delhi: Concept Publishing Company; 2009.

28. Scoville RP, Gordon AM. Children's understanding of factive presuppositions: an experiment and a review. J Child Lang. 1980;7(2):381-399.

29. Natsopoulos D. Processing implications and presuppositions by schoolchildren and adults: A developmental cross-linguistic comparison. J Psycholinguist Res. 1987;16(2):133-164.

30. Karttunen L, Verbs I. Implicative Verbs. Language. 1971;47(2): 340-358.

31. Cheung H, Chen HC, Yeung W. Relations between mental verb and false belief understanding in Cantonese-speaking children. J Exp Child Psychol. 2009;104(2):141-155.

32. Nagel J. Factive and nonfactive mental state attribution. Mind Lang. 2017;32(5):525-544.

33. Williamson T. Knowledge and Its Limits. New York: Oxford University Press; 2000.

34. Egre P. Question-embedding and factivity. Grazer Philosophische Studien. 2008;77(1):85-125. 
35. Carpendale JI, Lewis C. Constructing an understanding of mind: the development of children's social understanding within social interaction. Behav Brain Sci. 2004;27(1):79-96.

36. Limber J. The genesis of complex sentences. In: Moore TE, editor. Cognitive Development and the Acquisition of Language. New York: Academic Press; 1973:169-185.

37. Shatz M, Wellman HM, Silber S. The acquisition of mental verbs: a systematic investigation of the first reference to mental state. Cognition. 1983;14(3):301-321.

38. Schwanenflugel PJ, Henderson R, Fabricius WV. Developing theory of mind in older childhood: Evidence from verb extensions. Dev Psychol. 1998;34(3):512-524.

39. de Villiers J. The Interface of Language and Theory of Mind. Lingua. 2007;117(11):1858-1878

40. Lohmann $\mathrm{H}$, Tomasello $\mathrm{M}$. The role of language in the development of false belief understanding: a training study. Child Dev. 2003;74(4): 1130-1144.

41. Slaughter V, Peterson CC, Mackintosh E. Mind what mother says: narrative input and theory of mind in typical children and those on the autism spectrum. Child Dev. 2007;78(3):839-858.

42. Naigles L. Children use syntax to learn verb meanings. J Child Lang. 1990;17(2):357-374.

43. Astington JW, Olson DR. Metacognitive and metalinguistic language: Learning to talk about thought. Appl Psychol. 1990;39(1):77-87.

44. Lovett SB, Flavell JH. Understanding and remembering: children's knowledge about the differential effects of strategy and task variables on comprehension and memorization. Child Dev. 1990;61(6): $1842-1858$

45. Schwanenflugel PJ, Fabricius WV, Alexander J. Developing theories of mind: understanding concepts and relations between mental activities. Child Dev. 1994;65(6):1546-1563.

46. Schwanenflugel PJ, Fabricius WV, Noyes CR. Developing organization of mental verbs: Evidence for the development of a constructivist theory of mind in middle childhood. Cogn Dev. 1996;11(2):265-294.

47. Burke DM, Shafto MA. Language and aging. In: Craik FIM, Salthouse TA, editors. The Handbook of Aging and Cognition. New Jersey: Lawrence Erlbaum Associates; 2008:373-443.

48. Cahana-Amitay D, Albert ML, Ojo EA, et al. Effects of hypertension and diabetes on sentence comprehension in aging. J Gerntol B Psychol Sci Soc Sci. 2013;68(4):513-521.

49. Bahlmann J, Mueller JL, Makuuchi M, Friederici AD. Perisylvian functional connectivity during processing of sentential negation. Front Psychol. 2011;2:104.

50. Logie RH. Visuo-Spatial Working Memory. Aberdeen: Psychology Press; 1995.

51. Potter MC. Very short-term conceptual memory. Mem Cognit. 1993;21(2):156-161.

52. Mikels JA, Reuter-Lorenz PA, Beyer JA, Fredrickson BL. Emotion and working memory: evidence for domain-specific processes for affective maintenance. Emotion. 2008;8(2):256-266.

53. Salthouse TA. The aging of working memory. Neuropsychology. 1994;8(4):535-543.

54. Kemper S, Kemtes KA. Limitations on syntactic processing. In: Kemper S, Kliegl R, editors. Constraints on Language: Aging, Grammar, and Memory. Boston, MA: Kluwer Academic Publishers; 1999:79-106.

55. Waters G, Caplan D. The relationship between age, processing speed, working memory capacity, and language comprehension. Memory. 2005;13(3-4):403-413.

56. Vasishth S, Suckow K, Lewis RL, Kern S. Short-term forgetting in sentence comprehension: Crosslinguistic evidence from verb-final structures. Lang Cogn Process. 2010;25(4):533-567.

57. van Dyke JA, Johns CL, Kukona A. Low working memory capacity is only spuriously related to poor reading comprehension. Cognition. 2014;131(3):373-403.

58. Bar-Anan Y, Wilson TD, Gilbert DT. The feeling of uncertainty intensifies affective reactions. Emotion. 2009;9(1):123-127.
59. Baddeley A. Working memory and language: an overview. J Commun Disord. 2003;36(3):189-208.

60. Folstein MF, Folstein SE, McHugh PR. "Mini-mental state". A practical method for grading the cognitive state of patients for the clinician. J Psychiatr Res. 1975;12(3):189-198.

61. Fountoulakis KN, Tsolaki M, Chantzi H, Kazis A. Mini Mental State Examination (MMSE): A validation study in Greece. Am J Alzheimers Dis Other Demen. 2000;15(6):342-345.

62. Fountoulakis KN, Tsolaki M, Iacovides A, et al. The validation of the short form of the Geriatric Depression Scale (GDS) in Greece. Aging Clin Exp Res. 1999;11(6):367-372.

63. Sheikh JI, Yesavage JA. Geriatric Depression Scale (GDS): recent evidence and development of a shorter version. Clin Gerontol. 1986;5:165-173.

64. Nazlidou EI, Moraitou D, Natsopoulos D, Papantoniou G. Social cognition in adults: the role of cognitive control. Hell J Nucl Med. 2015;18(Suppl 1):109-121.

65. Pickering S, Gathercole SE. Working Memory Test Battery for Children $(W M T B-C)$. London: Psychological Corporation; 2001

66. Masoura EV, Kosmidis MH, Tsotsi S, et al. Tasks for the assessment of working memory: Development of normative data for the Greek population. Paper presented at: the 12th Panhellenic Conference for Psychological Research; May 14-17, 2009; Volos, Greece.

67. Stavrakaki S, Megari K, Kosmidis MH, Apostolidou M, Takou E. Working memory and verbal fluency in simultaneous interpreters. J Clin Exp Neuropsychol. 2012;34(6):624-633.

68. IBM Corp. IBM SPSS Statistics for Windows. Version 21.0. Armonk, NY: IBM Corp; 2012.

69. Bentler PM. EQS 6.1 Structural Equations Program Manual. Encino, CA: Multivariate Software, Inc.; 2005.

70. Brown TA. Confirmatory Factor Analysis for Applied Research. New York: The Guilford Press; 2006.

71. Bollen KA. Overall fit in covariance structure models: Two types of sample size effects. Psychol Bull. 1990;107(2):256-259.

72. Kline R. Principles and Practice of Structural Equation Modeling. 2nd ed. New York: The Guilford Press; 2005.

73. Moraitou D, Papantoniou G. Mindfulness and action control in young, middle-aged, and old adults: An examination of their relationship to attentional bias towards emotional information. Res Psychol. 2010;4:591-626.

74. Hale CM, Tager-Flusberg $H$. The influence of language on theory of mind: a training study. Dev Sci. 2003;6(3):346-359.

75. Hanna R. Rationality and Logic. Cambridge, MA: The MIT Press; 2009 .

76. Zwaan RA, Radvansky GA. Situation models in language comprehension and memory. Psychol Bull. 1998;123(2):162-185.

77. Haegeman L. The syntax of n-words and the Neg criterion. In: Forget D, Hirschbühler P, Martineau F, Rivero ML, editors. Negation and Polarity, Syntax and Semantics. Amsterdam: John Benjamins; 1997: 115-138.

78. Pollock JY, Movement V. Universal grammar, and the structure of IP. Linguistic Inquiry. 1989;20(3):365-424.

79. Carpenter PA, Just MA, Keller TA, Eddy WF, Thulborn KR. Time course of fMRI-activation in language and spatial networks during sentence comprehension. Neuroimage. 1999;10(2):216-224.

80. Christensen KR. Negative and affirmative sentences increase activation in different areas in the brain. J Neurolinguistics. 2009;22(1):1-17.

81. Nakano H, Saron C, Swaab TY. Speech and span: working memory capacity impacts the use of animacy but not of world knowledge during spoken sentence comprehension. J Cogn Neurosci. 2010;22(12): 2886-2898.

82. Newman SD, Malaia E, Seo R, Cheng H. The effect of individual differences in working memory capacity on sentence comprehension: an FMRI study. Brain Topogr. 2013;26(3):458-467.

83. Baddeley A. Working Memory, Thought, and Action. Oxford: Oxford University Press; 2007. 
Neuropsychiatric Disease and Treatment

Dovepress

\section{Publish your work in this journal}

Neuropsychiatric Disease and Treatment is an international, peerreviewed journal of clinical therapeutics and pharmacology focusing on concise rapid reporting of clinical or pre-clinical studies on a range of neuropsychiatric and neurological disorders. This journal is indexed on PubMed Central, the 'PsycINFO' database and CAS,

and is the official journal of The International Neuropsychiatric Association (INA). The manuscript management system is completely online and includes a very quick and fair peer-review system, which is all easy to use. Visit http://www.dovepress.com/testimonials.php to read real quotes from published authors.

Submit your manuscript here: http://www.dovepress.com/neuropsychiatric-disease-and-treatment-journal 